\title{
Rethinking medical audit: the goal is efficiency
}

\author{
Gavin Mooney, Mandy Ryan
}

Last year in this journal Hopkins ${ }^{1}$ reviewed the various approaches to "medical audit", and looked at how such audit is likely to develop over the next few years. The essence of his article seems to be that medical audit, if successful, should improve the quality of care. However, Hopkins can provide no evidence that any of the three approaches to medical audit which he outlines achieves this objective. He notes that reviewing medical records "can only give a general impression of the quality of care in an institution"; that "the promulgation of guidelines of good practice does not necessarily change practice"; and that, while the provision of information systems "will almost certainly improve the quality of recording of hospital activity ... there is as yet no generally accepted view about what data sets are required to reflect usefully the quality of clinical care".

Hopkins concludes that he "has taken a somewhat gloomy approach to the difficulties of medical audit". However, in an effort to be more optimistic, he states that in his view "the best audit package that a health district can at present institute may be a regular case record by an assessor, probably from a neighbouring district." And he continues that for all their drawbacks "such reviews have been shown to improve and maintain the quality ..." not unfortunately, as we had hoped, of patient care but ". . . of the written record"!

The three approaches to medical audit outlined by Hopkins involve only medical doctors. Clearly, if medical audit is only for doctors, then we, as economists, have no business writing about it. However, we would argue that since medical audit is about (or should be about) maximising benefits to patients with available resources, we have a role in discussing it. We want to comment on medical audit, since we believe that Hopkins has ignored two crucial questions. Namely, what is best medical practice? and how can doctors be got to practice it? Only by considering these two questions can we be sure that medical audit will increase the quality of health care or, as we would prefer to put it, the efficiency of health care. In the absence of such questions we have no way of judging whether change brought about by medical audit improves or worsens medical practice.

In the next section we discuss the concept of "best medical practice" and its importance to medical audit. Thereafter we examine how best medical practice, once defined, can be achieved, and finally we look at how medical audit is being implemented in the United Kingdom and suggest areas for future research and discussion. This paper should be of interest to all those involved in medical audit.

What is best medical practice?

While we would not suggest that there is a single answer to the question "what is best medical practice?", we do believe that there is a need for debate around the issue. The need for this debate is strengthened by the fact that, faced with similar patients, individual members of the medical profession differ so much in what they $\mathrm{do}^{2-4}$ They cannot all be right; they cannot all be practising best medicine.

All three approaches to medical audit outlined by Hopkins ignore this question. However, without addressing it, we cannot conduct medical audit effficiently. This point is clear if we consider Hopkins' approaches to medical audit. If a review of medical records is undertaken, what is to be taken as good practice? Is it what the average doctor is doing? Or is it what one of the outliers is doing? If guidelines of good medical practice are to be promulgated or clinicians are to be provided with information systems, what should such guidelines/information say? Again, should such guidelines/information assume that what the average doctor is doing is what all doctors should be practising?

So the problems of not first stating what constitutes best medical practice are clear. But what is best medical practice? One of the most striking features of a series of articles on this topic edited by one of us $(\mathrm{GM})^{5}$ was how many of those writing felt that best medical practice should be defined as efficient medical practice. Best medical practice, defined in this way, means maximising benefits to society with available resources. Thus, crucial here is the point that "ideal" medical practice cannot be achieved given limited resources, and that what we are striving for is "best medical practice" given the resources available. Yet if one examines medical textbooks, the concept of efficiency is seldom mentioned. And when it is, it is not clear how it is defined.

This brings us into a further debating arena, namely that of what is meant by benefits from the provision of health care, ie, what is it we are maximising? There is a tendency for doctors to assume that health care is solely about healthabout the prevention and treatment of disease. Oddly it is a view echoed by those health economists who argue that priority setting for health care can be achieved purely on the basis of cost per QALY league tables $(\mathrm{QALY}=$ Quality 
Adjusted Life Year). Such logic assumes that there is nothing produced in health care apart from QALYs, ie, health (see, for example, Williams ${ }^{6}$ ). However, we would argue that there are other benefits. These include the provision of information, reassurance, patient autonomy, and indeed anything that adds to the welfare of the patients. For example, can terminally ill cancer patients not get more or less benefit depending on the extent to which they emerge with dignity from their treatments-even if their health status is the same?

While we recognise that such factors as information, reassurance and dignity might not take on the same importance to patients as health status, and that their relative importance may vary from one situation to another and from one patient to another, they ought not to be ignored. In deciding best medical practice, patients' happiness is paramount. After all, in any other market (eg, the market for apples or cars) the consumer has the goal of maximising benefit or welfare. The main difference between such markets and the market for health care is that in the former the consumers are normally ready, willing and able to make choices. However, in the health care market it is frequently the case that the consumer has neither the knowledge nor (often) the desire to behave in this way and relies on the doctor to act as his or her agent. ${ }^{78}$ The role of that agent is then to help to maximise the welfare of the patients, which may be different from maximising their health.

But how is the patient's welfare to be defined? This is not clear to us. What is clear is that it should be the patient's values or preferences that count and not the doctor's/agent's. That is, what is best has to involve value judgements, and, in the context of maximising the patient's welfare, it should be the patient's value judgements that are used to decide on "best".

We equate this view not with patient sovereignty (where the patient chooses which treatment to undergo with the advice of the doctor) but with patient autonomy (where the patient has the choice of saying "yes, I want to decide, doctor" or "I can't or don't want to decide, doctor; you do it for me").

This area of patient autonomy, sovereignty, informed consent and "consumerism" needs much greater research and discussion than we can devote to it in this article. In the wake of the NHS white paper, Working for patients, ${ }^{9}$ giving patients choice is fashionable. But what that means for patient care and medical audit does not appear to have been thought through. ${ }^{78}$

In a world of unlimited resources, the doctor/ agent could consider each individual patient in isolation when deciding on which medical practice to pursue. However, in the real world there are resource constraints and consequently costs that must be considered in determining best medical practice as opposed to ideal medical practice. Thus, having defined benefits in terms of the preferences of patients, costs need to be considered. By cost we mean the benefit forgone in the next best use of resources. We would argue that we have to leave it to the medical profession to judge the (opportunity) cost of treatment, taking account of patient preferences. What this means is that the doctor has to assess the relative benefits of one patient against another, even if it is the patient who decides with the help of his/her agent what is individually best for him/her. In other words the doctor has to make the "interpatient" comparisons on which the opportunity cost in this context is based.

Efficiency in the clinical arena thus means maximising the benefit from the resources available where the benefit is assessed by the patient (albeit through a perfect agent) and where the cost (in terms of benefits forgone) is assessed by the doctor (in the sense of the interpersonal or interpatient comparison of benefits). Only when efficiency is attained will best medical practice, given limited resources, be achieved.

\section{Getting there}

Assuming that we can determine what constitutes best medical practice, how do we get doctors to practice it? One option would be to provide clinicians with information on best medical practice. Within the context of medical practice variations, Wennberg et $a l^{10}$ have argued that exposing clinicians to information on the extent and effects of variations will reduce variations. That is, he argues that the provision of information can change behaviour.

However, as Evans ${ }^{11}$ so correctly states in relation to practice variations:

"Knowing is not the same as doing (emphasis added). The most striking fact about the large and extensively documented variations in patterns of medical practice, throughout the developed world, is the minimal impact this information has had on health policy."

Evans is referring here to the many publications that have appeared in medical journals over the last 20 years on the extent of medical practice variations. Despite this information, marked variations in medical practice still exist. Such variations have been found with respect to many common surgical procedures, ${ }^{12} 13$ hospital discharge rates, ${ }^{14}$ patterns of general practitioner referrals, ${ }^{15-17}$ and prescribing rates ${ }^{18}$ in the United Kingdom. Indeed, several studies have found that giving clinicians information has only a limited effect on their behaviour. For example, Harris $e a^{19}$ studied the extent to which general practitioners changed their prescribing habits when given regular information on their prescribing and a chance to discuss this information. While this study found that they changed some of their prescribing habits initially, a follow up study of the same doctors two years later revealed that most of the effects of the intervention had disappeared. ${ }^{20} \mathrm{~A}$ similar result was found by Wickings et $a^{21}$ with respect to providing doctors with costing information.

Getting doctors to practice best medicine requires that they are not only provided with information on what constitutes best medical practice, but that they are also given the right set of incentives to persuade them to move their behaviour closer to this. The North of England study of standard settings found that providing the medical profession with standards set internally provides more of an incentive to change 
behaviour than does external standard setting. ${ }^{22}$ There is also some evidence that the medical profession responds to financial incentives. For example Rice ${ }^{23}$ showed that physicians under Medicare changed their behaviour when their fees changed, and Krasnik et $a l^{24}$ indicated that Copenhagen general practitioners changed their behaviour in terms of treatments, diagnostic tests, and referrals when they moved from a wholly per capita remuneration system to a part per capita, part fee per item system.

Given that incentive systems have been shown to work, what is needed is the implementation and testing of such systems to ensure that best medical practice, defined as efficient medical practice, is the goal of medical decision making. If financial incentives are to be adopted, research is needed on what level and form of payments for doctors will lead to the optimal level of medical practice.

\section{Discussion}

For any form of medical audit to be effective two questions need to be resolved. Firstly, what is best medical practice? And secondly, what is the right set of incentives to get doctors to conduct best medical practice?

Research is needed to answer these two questions. ${ }^{5}$ Despite the fact that the last few years have seen an explosion of interest in medical audit by policy makers, to our knowledge there has been little attempt to address these questions. The result has been that there is no way of judging whether things are better or worse as a result of audit.

Without knowledge on these two issues, medical audit lacks direction. This is already evident in the United Kingdom on a number of fronts. In his article, Hopkins ${ }^{1}$ notes that the Department of Health is already investing large amounts of money on large scale information systems in the hope (belief) that it "will in some way do audit". He states that the sum allocated to his own health region for salaries for audit for the next three years is only slightly more than the sum allocated for non-recurring costs for computer sytems. At no point does it appear that there has been any consideration of what best medical practice is. The hope seems to be that, by providing such information systems, improvements in medical practice will somehow "emerge".

A similar initiative is being undertaken in the Grampian area. Variations in general practitioner referral rates have led the government to make a number of proposals aimed at "improving" the referral process. The Grampian Referrals Initiative Project (GRIP) aims to evaluate two basic initiatives "designed to improve the referral process". The first asks four specialists to draft guidelines to help general practitioners decide whether to refer patients suffering from one of four tracer conditions. In the second, general practitioners receive information comparing their referral patterns with aggregate levels in the region. Both of these initiatives seem to have ignored the question of what is best medical practice. The first appears to rely on specialists defining "model programmes" or "good practice" in the hope that providing such knowledge will bring that good practice about. The second has the implicit assumption that being an outlier is a bad thing, that high referring general practitioners make an excessive use of NHS resources, while low referring general practitioners deprive their patients of needed care. Yet what the doctor somewhere in the middle is doing is not necessarily best.

In conclusion we would emphasise that we are not opposed to medical audit. It is the way that it is currently being pursued that concerns us. First, there is a lack of a clear justification or objective for medical audit. That needs to be resolved and in doing so we propose that the goal of medical audit is "best medical practice" defined as efficient medical practice. Second, any system of medical audit aimed at efficient practice needs to incorporate the right set of incentives to get doctors interested in being efficient. To achieve the optimal incentive system, an economic evaluation of any proposed incentive system is required. This was illustrated by the North of England study of standard setting which showed that internal standard setting is to be preferred to external standard setting. ${ }^{22}$ However this aspect of medical audit is sadly missing from current discussions.

There is a need for some more reasoned discussion of both the objectives and the implementation of medical audit. Otherwise Hopkins' pessimism will continue to prove wholly justified.

We are grateful to Cam Donaldson for comments on an earlier version of this paper. The Unit is funded by the Chief Scientist Office of the Scottish Home and Health Department; however, the opinions expressed in this communication are those of the authors, not the SHHD.

1 Hopkins A. Approaches to medical audit. $\mathcal{f}$ Epidemiol Community Health 1991; 45: 1-3.

2 Ryan M. Research into medical practice variations: where now? A paper for debate. Health Economics Research Unit Discussion Paper No. 04/91. Aberdeen: University of Aberdeen, 1991.

3 Copenhagen Collaborating Centre. Bibliography on regional variations in health care. Copenhagen: Institute of Social Medicine, 1985 and 1987.

4 Ham C. Health care variations: assessing the evidence. London: The Kings Fund Institute (Research Report Number 2), 1988.

5 Mooney G, Loft A. Best medical practice is importantwhatever it is. Int $\mathcal{f}$ Health Planning Manage 1989; 4: 247-52.

6 Williams $A$. Economics of coronary artery bypass grafting. BMF 1985; 291: 326-9.

7 Lupton D, Lloyd P, Donaldson C. Caveat emptor or blissful ignorance? Patients and the consumerist ethos. Soc Sci Med 1991; 33: 559-68.

8 Donaldson C, Lloyd P, Lupton D. Primary health care consumerism amongst elderly Australians. Age Ageing 1991; 20: 280-6.

9 Secretaries of State for Health, Wales, Northern Ireland and Scotland. Working for patients. London: HMSO, Cmnd 555: 1989.

10 Wennberg JE, Barnes BA, Zubkoff M. Professional uncertainty and the problems of supplier-induced demand. Soc Sci Med 1982; 16: 811-24.

11 Evans RG. The dog in the night: medical practice variations and health policy. In: Andersen TF, Mooney G, eds. The challenges of medical practice variations. London: Macmillan, 1990: 117-52.

12 McPherson K, Strong PM, Jones L, Briton BJ. Do cholecystectomy rates correlate with geographic variations in prevalence of gallstones? $\mathcal{F}$ Epidemiol Community Health 1985; 39: 179-82.

13 McPherson K, Wennberg JE, Hovind OB, Clifford P Small-area variations in the use of common surgical procedures: an international comparison of New procedures: an international comparison of New England,

14 Ryan M. A preliminary analysis of variations in discharge rates in Scotland. Discussion Paper No. 03/91 Aberdeen rates in Scotland. Discussion Paper No. 03/91 Aberdeen 1991 .

15 Gillam DM. Referral to consultants-the National Health Service versus private practice. $\exists R$ Coll Gen Pract $1985 ; 35$ : 15-18. 
16 Wilkin D, Smith AG. Variations in general practitioners' referral rates to consultants. $\mathcal{I} R$ Coll Gen Pract 1987; 37 350-3.

17 Noone A, Goldacre M, Coulter A, Seagroatt V. Do referra rates vary widely between practices and does supply of services affect demand? A study in Milton Keynes and the Oxford Region. I R Coll Gen Pract 1989; 39: 404-7. 18 Forster DP, Frost CEB. Use of regression analysis to explain practitioner committees. Br f Gen Pract 1991; 41: 67-71.

19 Harris CM, Jarman B, Woodman E. Prescribing - a suitable case for treatment. (Occasional paper 24.) London: Royal College of General Practitioners, 1984.

20 Harris CM, Jarman B, Woodman E. Prescribing-a case for prolonged treatment . $₹ R$ Coll Gen Pract 1985; 35: 284-7.

\section{Dr Hopkins responds}

I have sympathy with many of the arguments advanced by Mooney and Ryan, but I do believe that they start from a false premise in redefining medical audit, as "maximising benefits to patients with available resources". Although information about patients may be aggregated for audit purposes, the primary unit is the quality of care provided to an individual patient. Resources certainly come into the equation, as to order an inappropriate investigation, for example, is certainly care of poor quality. However, the allocation of available resources to classes of patients is a moral and political decision. Physicians and other medical personnel are only one set of Thespians on this particular stage.

Mooney and Ryan state that I have ignored two crucial questions, the first of which is "What is best medical practice?" Best medical practice must be determined by research. That research may be basic biomedical research, randomised controlled trials, research into different ways of delivering health care, and so on. However, audit determines whether in the management of an individual patient or patients of a chosen class (characterised by date of admission, diagnosis, etc) care of good quality has been delivered (as determined by research). My editorial was principally addressing the difficulties that were likely to be encountered in establishing such audits.

I do not understand the difficulties that Mooney and Ryan have with clinical guidelines. They propose that guidelines might reflect "what
21 Wickings I, Coles JM, Flux R, Howard L. Review of clinical Wickings I, Coles JM, Flux R, Howard L. Review of clinica 22 budgeting and costing experiments. $B M F$ 1983; 287: 576 . General Practice. Final Report: III-The effects of setting and implementing clinical standards. Report No. 42, Health Care Research Unit, University of Newcastle Upon Tyne, 1990.

23 Rice TH. The impact of changing Medicare reimbursement rates on physician-induced demand. Med Care 1983; 21 : 803-15.

24 Krasnik A, Groenewegen PP, Pedersen PA, et al. Changing practice. BMF 1990; 300: 1698-701.

the average doctor is doing?" This clearly must not be the case. Guidelines must be based upon the best available evidence of practices that effectively improve the health status of a patient. All doctors should be practising effective medical care. Many studies have shown that the "average doctor" is often deviant in this respect.

I would argue also that Mooney and Ryan are under a misapprehension when their "logic assumes that there is nothing in health care apart from QALYs, ie. health ... however, we would argue that there are other benefits. These include the provision of information, reassurance, patient autonomy..." Any measure of health status worthy of the name includes the benefits of reassurance in terms of relief of anxiety, and improvement in patient autonomy. Here, two health economists seem to be taking a much narrower view of health (as physical health alone) than do most doctors.

I agree with much of what Mooney and Ryan write, notably the importance of patient preferences in determining choice of therapy. I also agree that the medical profession is well placed to judge the (opportunity) cost of treatment, taking into account these preferences, and that there is a need for a major research initiative in order to discover effective ways of altering physician behaviour.

ANTHONY HOPKINS

Director, Research Unit

Royal College of Physicians 